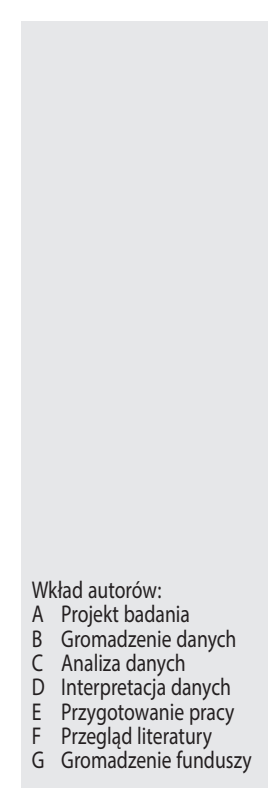

\title{
Zastosowanie 24-godzinnej pH-metrii gardłowej w diagnostyce pacjentów z dolegliwościami ze strony gardła i krtani
}

\section{The application of 24-hour pharyngeal $\mathrm{pH}$-monitoring in the diagnosis of patients with pharyngeal and laryngeal complaints}

\author{
Elżbieta Włodarczyk', Henryk Skarżyński² \\ ${ }^{1}$ Instytut Fizjologii i Patologii Słuchu, Światowe Centrum Słuchu, Klinika Rehabilitacji, \\ Warszawa/Kajetany \\ ${ }^{2}$ Instytut Fizjologii i Patologii Słuchu, Światowe Centrum Słuchu, Klinika Oto-Ryno- \\ Laryngochirurgii, Warszawa/Kajetany
}

\section{Streszczenie}

Wprowadzenie: Refluks krtaniowo-gardłowy (LPR) jest przewlekłym procesem chorobowym polegającym na wstecznym ruchu treści płynnej lub gazowej żołądka poprzez przełyk do gardła i krtani, co wywołuje ostre lub przewlekłe objawy zapalenia śluzówki krtani i gardła. W ostatnich latach coraz szerzej stosowana jest 24-godzinna pH-metria gardłowa, która umożliwia monitorowanie pozaprzełykowych manifestacji GERD.

Cel: Ocena częstości występowanie LPR u pacjentów zgłaszających się z powodu dolegliwości ze strony gardła i krtani, takich jak: ból, pieczenie, przewlekła lub nawracająca chrypka, z zastosowaniem 24-godzinnej pH-metrii gardłowej.

Materiał i metody: Badaniem objęto 84 chorych (67 kobiet, 17 mężczyzn) w wieku 18-71 lat (średnia wieku - 48 lat) z dolegliwościami ze strony gardła i krtani. Pacjenci proszeni byli o wypełnienie kwestionariusza Skali Dolegliwości Refluksowych (RSI). Na podstawie obrazu krtani w badaniu wideolaryngostroboskopii wypełniono kwestionariusz Skali Patologii Refluksowej (RFS). U wszystkich pacjentów wykonano 24-godzinną $\mathrm{pH}$-metrię gardłową. LPR rozpoznano na podstawie Ryan Score.

Wyniki: U ponad połowy pacjentów (59,5\%) rozpoznano LPR w pozycji pionowej (Ryan Score >9,41). Biorąc pod uwagę wyniki skali RSI, najczęściej zgłaszaną dolegliwością było chrząkanie, zaraz potem nadmierna ilość wydzieliny, chrypka oraz uczucie przeszkody w gardle. W obrazie krtani dominowały przede wszystkim takie objawy jak: rumień/przekrwienie szczególnie w okolicy chrząstek nalewkowych (ale również innych struktur krtani), przerost spoidła tylnego, obrzęk fałdów głosowych i obrzęk krtani.

Wnioski: W diagnostyce pacjentów zgłaszających się z powodu dolegliwości ze strony gardła i krtani należy brać pod uwagę występowanie refluksu krtaniowo-gardłowego, szczególnie jeżeli występuje korelacja pomiędzy zgłaszanymi dolegliwościami a obrazem endoskopowym krtani. W diagnostyce LPR użytecznym badaniem jest 24-godzinna pH-metria.

Słowa kluczowe: refluks krtaniowo-gardłowy • 24-godzinna pH-metria gardłowa • Skala Dolegliwości Refluksowych • Skala Patologii Refluksowej

\footnotetext{
Abstract ic or recurrent hoarseness using 24-hour pharyngeal pH-monitoring.

Adres autora: dr n med. Elżbieta Włodarczyk, Klinika Rehabilitacji, Światowe Centrum Słuchu, Instytut Fizjologii i Patologii Słuchu, ul. Mokra 17, Kajetany, 05-830 Nadarzyn, e-mail: e.wlodarczyk@ifps.org.pl
}

Introduction: Laryngopharyngeal reflux (LPR) is a chronic disease process that represents the retrograde movement of stomach fluid or gas through the esophagus to the pharynx and larynx, causing acute or chronic symptoms of laryngitis. In recent years, the 24hour $\mathrm{pH}$-monitoring has been gaining popularity, which enables the monitoring of extra-esophageal GERD manifestations.

Aim: To assess the prevalence of LPR in patients presenting with pharyngeal and laryngeal symptoms such as pain, burning, chron-

Material and methods: The study involved 84 patients (67 women, 17 men), aged 18-71 years (mean age - 48 years) with symptoms of the pharynx and larynx. Patients were asked to complete the Reflux Symptoms Index (RSI) questionnaire. The larynx was 
assessed by videolaryngostroboscopy based on the Reflux Finding Score (RFS). 24-hour pharyngeal pH-monitoring was performed in all patients. LPR was diagnosed on the basis of the Ryan Score.

Results: For more than half of the patients (59.5\%), the LPR was diagnosed in the vertical position (Ryan Score > 9.41). Based on the results of the RSI Scale, grunting was the most frequently reported complaint, followed by excessive discharge, hoarseness and a feeling of obstruction in the throat. The results of the RFS Scale showed that the laryngeal image was dominated by erythema / hyperemia, especially in the area of the tincture cartilage (but also other structures of the larynx), posterior commissural hypertrophy, edema of the vocal folds and laryngeal edema.

Conclusions: In the diagnosis of patients presenting with pharyngeal and laryngeal symptoms, the occurrence of laryngopharyngeal reflux should be taken into account, especially if there is a correlation between the reported symptoms and the endoscopic image of the larynx. The 24-hour pharyngeal $\mathrm{pH}$-monitoring is a useful test in the diagnosis of LPR

Key words: laryngopharyngeal reflux • 24-hour pharyngeal-monitoring • Reflux Symptoms Index • Reflux Finding Score

\section{Wprowadzenie}

Refluks krtaniowo-gardłowy (ang. laryngopharyngeal reflux, LPR) jako termin medyczny został wprowadzony przez Amerykańską Akademię Otolaryngologów Chirurgów głowy i Szyi w 2002 r. [1]. LPR jest przewlekłym procesem chorobowym, w którym występuje wsteczny ruch treści płynnej lub gazowej żołądka poprzez przełyk do gardła i krtani [2], co wywołuje ostre lub przewlekłe objawy zapalenia śluzówki krtani. Uważa się, że uszkodzenia struktur krtani powodowane są głównie przez działanie pepsyny, a nie kwasu żołądkowego. Na skutek tego oddziaływania dochodzi do obrzęków struktur krtani i metaplazji nabłonka urzęsionego w kierunku nabłonka płaskiego, gruczoły błony śluzowej przerastają, a następnie zanikają. Do najczęściej obserwowanych objawów uszkodzenia śluzówki krtani należą: chrypka, pochrząkiwanie, uczucie ciała obcego, przewlekły kaszel, spływanie wydzieliny po tylnej ścianie gardła, zaburzenia połykania (dysfagia) [3]. Objawy te powodowane są bezpośrednim oddziaływaniem peptycznej treści żołądka, ale mogą powstawać również na drodze odruchowej. Jednocześnie u większości tych pacjentów nie obserwuje się dolegliwości charakterystycznych dla choroby refluksowej przełyku (ang. gastroesophageal reflux disease, GERD) takich jak: zgaga, pieczenie w żołądku, odbijanie. Uważa się, że około $10 \%$ pacjentów laryngologicznych i ponad $50 \%$ pacjentów z zaburzeniami głosu ma dolegliwości spowodowane LPR [4].

Do opisu dolegliwości związanych z refluksem krtaniowo-gardłowym Belafsky i wsp. [5] opracowali Skale Dolegliwości Refluksowych (ang. Reflux Symptoms Index, RSI). Diagnostykę LPR opiera się również na obrazie wideolaryngoskopowym krtani. Uważa się, że zaczerwienienie i obrzęk nalewek i okolicy międzynalewkowej, obrzęk i/ lub przekrwienie fałdów głosowych oraz innych struktur krtani może świadczyć o występowaniu u pacjenta LPR. Obecnie stosowanym narzędziem diagnostycznym do oceny jakościowych i ilościowych zmian w krtani jest $S k a$ la Patologii Refluksowej (ang. Reflux Finding Score, RFS) opracowana przez ten sam zespól, co skala RSI [2]. Obie stosowane skale były walidowane, jednak na stosunkowo małej liczbie pacjentów: skala RSI na 25 osobach, RFS - na 40. W diagnostyce GERD istnieje tzw. „złoty standard” diagnostyczny i jest nim dwusondowa 24-godzinna $\mathrm{pH}$-metria przełyku. Przyjmuje się spadek $\mathrm{pH}$ poniżej 4 jako kryterium potwierdzające GERD, natomiast refluks patologiczny jest potwierdzony, gdy liczba takich spadków pH jest większa niż 50 na dobę, a łączny czas utrzymywania się pH poniżej 4 wynosi godzinę. Te kryteria nie pozwalają jednak na diagnozowanie u pacjentów LPR [6]. $\mathrm{W}$ ostatnich latach coraz szerzej stosowana jest 24-godzinna pH-metria gardłowa, która umożliwia monitorowanie pozaprzełykowych manifestacji GERD.

\section{Cel pracy}

Celem pracy była ocena częstości występowanie LPR u pacjentów zgłaszających się z powodu dolegliwości ze strony gardła i krtani, takich jak: ból, pieczenie, przewlekła lub nawracająca chrypka, z zastosowaniem 24-godzinnej $\mathrm{pH}$-metrii gardłowej.

\section{Materiał i metoda}

Badaniem objęto 84 chorych (67 kobiet i 17 mężczyzn), w wieku 18-71 lat (średnia wieku - 48 lat), którzy zgłosili się do Kliniki Audiologii i Foniatrii Instytutu Fizjologii i Patologii Słuchu z powodu dolegliwości ze strony gardła i krtani. Najczęściej zgłaszanymi objawami były: chrypka, pieczenie w gardle, uczucie przeszkody w gardle, uczucie spływania wydzieliny po tylnej ścianie gardła, pochrząkiwanie. U wszystkich pacjentów zebrano wywiad dotyczący dolegliwości z zakresu chorób laryngologicznych, foniatrycznych i ogólnych. Pacjenci proszeni byli o wypełnienie kwestionariusza Skala Dolegliwości Refluksowych [5]. Pytania i skale odpowiedzi kwestionariusza RSI przedstawiono $\mathrm{w}$ tabeli 1 . Dokonano oceny krtani na podstawie obrazu wideolaryngostroboskopii, następnie wypełniono kwestionariusz Skala Patologii Refluksowej [2]. Pytania i skale odpowiedzi kwestionariusza RSI przedstawiono w tabeli 2. U wszystkich pacjentów wykonano 24-godzinną pH-metrię gardłową z użyciem Restech Dx-pH system. Jest to urządzenie służące do pomiaru $\mathrm{pH}$ gardła przy pomocy antymonowej sondy. Pomiar dokonywany jest w czasie rzeczywistym co $0,5 \mathrm{~s}$, a jego wykonanie jest możliwe zarówno w środowisku płynnym, jak i gazowym. W trakcie badania liczone są spadki pH (poniżej 5,5 dla pozycji pionowej i 5,0 dla pozycji poziomej) oraz czas ich trwania. LPR rozpoznajemy na podstawie Ryan Score [7], którego wartość obliczana jest na podstawie procentu czasu poniżej progu kwasowej ekspozycji w gardle, liczby zdarzeń (spadków pH) i długości ich trwania oddzielnie dla pozycji pionowej i poziomej.

Sonda pomiarowa została skalibrowana i umieszona zgodnie $\mathrm{z}$ instrukcją producenta. Kalibracja miała miejsce w roztworach o pH 7 i 4 . Wprowadzona do gardła na wysokość 5-10 mm poniżej języczka przez jamę nosową i umocowana (za pomocą Tegaderm) do policzka pacjenta. Urządzenie rejestrujące zostało przekazane w specjalnym 
Tabela 1. Skala Dolegliwości Refluksowych (RSI)

Table 1. The Reflux Symptoms Index (RSI)

\begin{tabular}{ll}
\hline \multicolumn{2}{c}{ Skala Dolegliwości Refluksowych wg Belafsky'ego } \\
\hline \multicolumn{1}{c}{ W jakim stopniu w ciągu ostatniego miesiąca wystąpiły u Pani/Pana następujące objawy: } \\
\hline 1. Chrypka lub problemy głosowe & 12345 \\
\hline 2. Chrząkanie & 12345 \\
\hline 3. Nadmierna ilość wydzieliny w gardle lub spływanie wydzieliny po tylnej ścianie gardła & 12345 \\
\hline 4. Zaburzenia połykania & 12345 \\
\hline 5. Kaszel po jedzeniu lub po położeniu się & 12345 \\
\hline 6. Zaburzenia oddychania & 12345 \\
\hline 7. Męczący kaszel & 12345 \\
\hline 8. Uczucie przeszkody lub ciasnoty w gardle & 12345 \\
\hline 9. Pieczenie/ból w klatce piersiowej, niestrawność, uczucie cofania się treści żołądkowej & 12345 \\
\hline
\end{tabular}

Tabela 2. Skala Patologii Refluksowej (RFS)

Table 2. The Reflux Finding Score (RFS)

\section{Skala Patologii Refluksowejwg Belafsky'ego}

1. Obrzęk okolicy podgłośniowej

$0=$ nieobecny

2 = obecny

2 = częściowa

2. Obliteracja kieszonki krtaniowej

4 = całkowita

3. Rumień/przekrwienie

2 = tylko w okolicy chrząstek nalewkowych

4. Obrzęk fałdów głosowych

$1=$ niewielki

2 = umiarkowany

3 = znaczny

$1=$ niewielki

5. Rozległy obrzęk krtani

2 = umiarkowany

6. Przerost spoidła tylnego

3 = znaczny

4 = obturujący

$1=$ niewielki

2 = umiarkowany

3 = znaczny

$4=$ obturujący

7. Ziarniniak/ziarnina

$0=$ nieobecny $/ \mathrm{a}$

2 = obecny/a

$0=$ nieobecna

8. Gęsta wydzielina śluzowa w krtani

2 = obecna

etui pacjentowi wraz z ustną i pisemną instrukcją obsługi. Pacjent proszony był o prowadzenie dzienniczka dotyczącego spożywanych w trakcie badania posiłków i przebywania $\mathrm{w}$ pozycji leżącej. W trakcie analizy danych odpowiednim oprogramowaniem okresy posiłków nie były brane pod uwagę (margines czasowy $5 \mathrm{~min}$ ).

\section{Wyniki}

\section{4-godzina pH-metria gardłowa}

W literaturze przyjmuje się różne kryteria rozpoznawania LPR na podstawie wyniku 24-godzinnej 

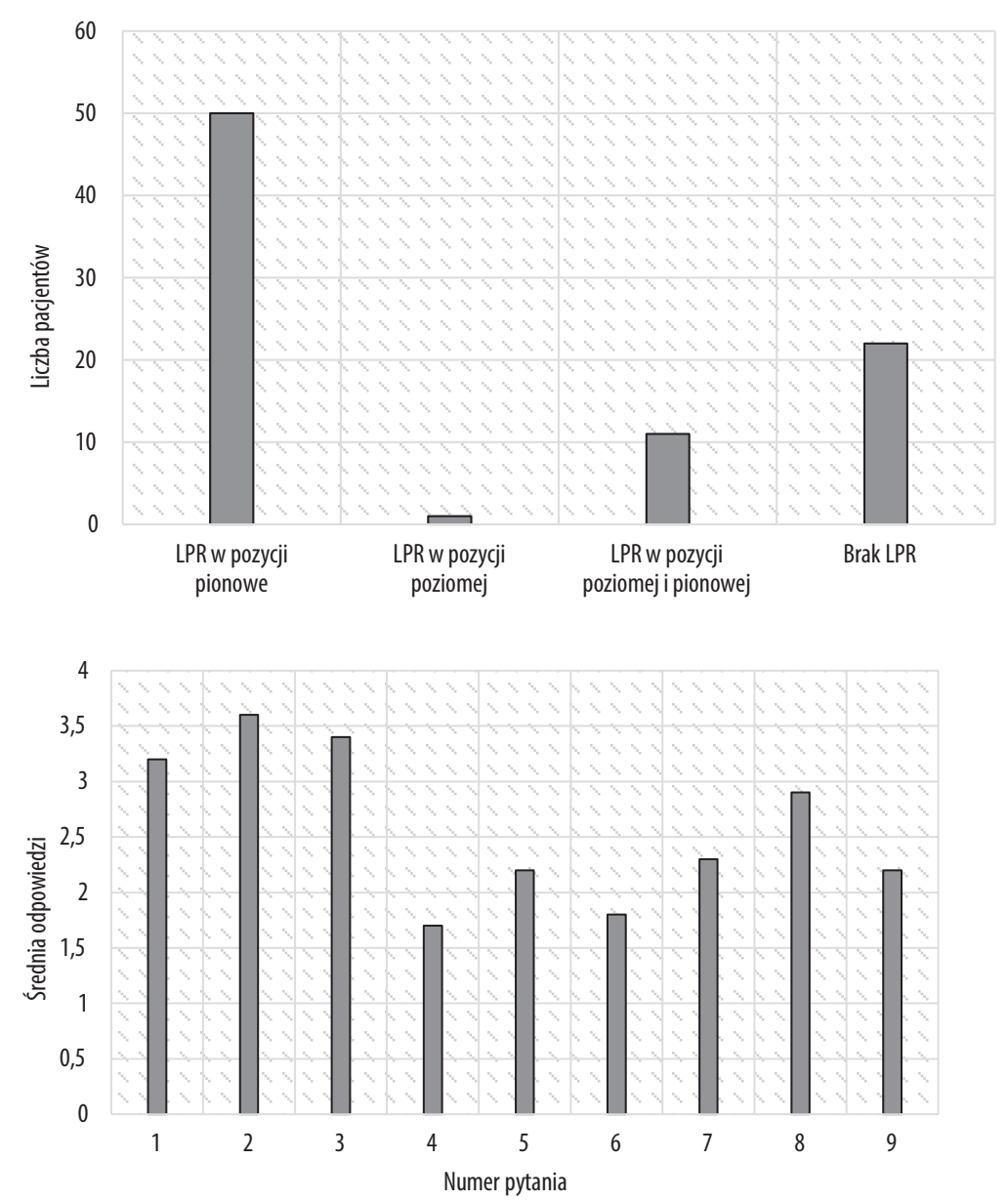

Rycina 1. Liczba pacjentów, u których zarejestrowano epizody refluksowe (LPR) w różnych pozycjach lub nie zarejestrowano ich wcale

Figure 1. Number of patients who had reflux episodes (LPR) in different positions or not at all
pH-metrii gardłowej. W niniejszej pracy przyjęto definicję LPR proponowaną przez producentów urządzenia pomiarowego:

- $\quad$ LPR w pozycji pionowej: Ryan Score pionowy $>9,41$;

- $\quad$ LPR w pozycji poziomej: Ryan Score poziomy $>6,8$.

Na podstawie tak przyjętych kryteriów u 50 (59,5\%) pacjentów zdiagnozowano LPR w pozycji pionowej, 1 (1,2\%) pacjent miał refluks w pozycji poziomej, u $11(13,1 \%)$ pacjentów występował refluks w obu pozycjach, a 22 (26,2\%) pacjentów nie miało refluksu (rycina 1).

Średnią wartość punktową poszczególnych dolegliwości zgłaszanych przez pacjentów i opisanych w skali RSI przedstawiono na rycinie 2 .

Z danych pokazanych na rycinie 2 wynika, że najczęściej zgłaszaną dolegliwością było chrząkanie, zaraz potem nadmierna ilość wydzieliny, chrypka oraz uczucie przeszkody w gardle.

Na podstawie badania wideostroboskopowego wypełniano kwestionariusz skali RFS (tabela 2) dla każdego pacjenta. Analizując wyniki skali RFS, zauważa się, że w obrazie krtani dominował rumień/przekrwienie, szczególnie w okolicy chrząstek nalewkowych (ale również innych struktur krtani), przerost spoidła tylnego, obrzęk fałdów głosowych i obrzęk krtani. Częstość występowania nieprawidłowości w krtani na postawie obrazu wideostroboskopowego przedstawiono w tabeli 3.

\section{Dyskusja}

W praktyce lekarza laryngologa i foniatry dość często zgłaszają się pacjenci z umiarkowanie nasilonymi dolegliwościami takimi jak: okresowe bóle gardła, uczucie pieczenia, spływanie wydzieliny po tylnej ścianie gardła, chrypka, pojawiającymi się okresowo lub utrzymującymi się przewlekle [8]. Pacjenci często zgłaszają chrypkę, która pojawia się $\mathrm{w}$ godzinach porannych, a w ciągu dnia stopniowo ustępuje. Objawy te nie są charakterystyczne dla LPR i mogą występować w chorobach infekcyjnych, alergicznych, nowotworowych, zakażeniach górnych i dolnych dróg oddechowych. Jednocześnie pacjenci ci negują występowanie typowych dla GERD dolegliwości gastrycznych, takich jak: zgaga, bóle zamostkowe czy regurgitacja kwaśnej treści pokarmowej żołądka do przełyku. Dopiero w 2006 r. gremium gastroenterologiczne stworzyło konsensus opisujący GERD i wskazujący na jego związki z refluksowym zapaleniem krtani (LPR). Autorzy wskazują, że u około 78\% pacjentów z zaburzeniami głosu możemy pH-metrycznie [9] potwierdzić występowanie LPR [10]. W naszym materiale również chrypka, zaraz po pochrząkiwaniu, była najczęściej zgłaszanym problemem.

W obrazie endoskopowym krtani w materiale własnym najczęściej obserwowano: przerost spoidła tylnego, obrzęk 
Tabela 3. Częstość występowania nieprawidłowości w krtani na postawie obrazu wideostroboskopowego

Table 3. The incidence of abnormalities in the larynx based on the videostroboscopic image

\begin{tabular}{lcc}
\hline Rodzaj nieprawidłowości & Obecność & Brak \\
\hline Obrzęk okolicy podgłośniowej & 9 & 75 \\
\hline Obliteracja kieszonki krtaniowej & 50 & 34 \\
\hline Rumień/przekrwienie & 62 - tylko okolice chrzastek nalewkowych & 6 \\
\hline Obrzęk fałdów głosowych & 67 & 17 \\
\hline Rozległy obrzęk krtani & 66 & 18 \\
\hline Przerost spoidła tylnego & 77 & 7 \\
\hline Ziarniniak/ziarnina & 5 & 79 \\
\hline Gęsta wydzielina śluzowa w krtani & 14 & 70 \\
\hline
\end{tabular}

fałdów głosowych oraz przekrwienie śluzówki. Podobne wyniki w swoich badaniach uzyskiwali również inni autorzy $[11,12]$. Przekrwienie w okolicy chrząstek nalewkowatych opisywane jest przez niektórych autorów jako podstawowy objaw LPR [13]. Również w przypadku dzieci wymienione objawy bardzo silnie korelowały $\mathrm{z}$ występowaniem refluksu krtaniowo-gardłowego [14]. W diagnostyce dolegliwości ze strony gardła i krtani 24-godzinna pH-metria gardłowa wydaje się użytecznym narzędziem diagnostycznym w sytuacji, kiedy zarówno dolegliwości pacjenta (np. na podstawie RSI), jak i obraz endoskopowy krtani (RFS) sugerują występowanie refluksu krtaniowo-gardłowego [15].

\section{Wnioski}

W diagnostyce pacjentów zgłaszających się z powodu dolegliwości ze strony gardła i krtani należy brać pod uwagę występowanie refluksu krtaniowo-gardłowego, szczególnie jeżeli występuje korelacja pomiędzy zgłaszanymi dolegliwościami a obrazem endoskopowym krtani. Użytecznym badaniem w diagnostyce LPR jest 24-godzinna $\mathrm{pH}$-metria gardłowa

\section{Piśmiennictwo}

1. Koufman JA, Aviv JE, Casiano RR, Shaw GY. Laryngopharyngeal reflux: position statement of the committee on speech, voice, and swallowing disorders of the American Academy of Otolaryngology-Head and Neck Surgery. Otolaryngol Head Neck Surg, 2002; 127(1): 32-5.

2. Belafsky PC, Postma GN, Koufman JA. The validity and reliability of the reflux finding Score (RFS). Laryngoscope, 2001; 111(8): 1313-7.

3. Bardhan KD, Strugala V, Dettmar PW. Reflux revisited: advancing the role of pepsin. Int J Otolaryngol, 2012: 646901.

4. Gupta R, Sataloff RT. Laryngopharyngeal reflux: current concepts and questions. Curr Opin Otolaryngol Head Neck Surg, 2009; 17(3): 143-8.

5. Belafsky PC, Postma GN, Koufman JA. Validity and reliability of the reflux symptom index (RSI). J Voice, 2002; 16(2): 274-7.

6. Reichel O, Issing WJ. Impact of different $\mathrm{pH}$ thresholds for 24-hour dual probe $\mathrm{pH}$ monitoring in patients with suspected laryngopharyngeal reflux. J Laryngol Otol, 2008; 122(5): 485-9.

7. Laryngopharyngeal Reflux and the RYAN Score - Restech, 2018; https://www.restech.com/laryngopharyngeal-reflux-and-the-ryan-score/ [dostęp: 2.08.2021].

8. Vakil N, Zanten SV van, Kahrilas P, Dent J, Jones R, Global Consensus Group. The Montreal definition and classification of gastroesophageal reflux disease: a global evidence-based consensus. Am J Gastroenterol, 2006; 101(8): 1900-20; quiz 1943.

9. Wiener GJ, Koufman JA, Wu WC, Cooper JB, Richter JE, Castell DO. Chronic hoarseness secondary to gastroesophageal reflux disease: documentation with 24-h ambulatory $\mathrm{pH}$ monitoring. Am J Gastroenterol, 1989; 84(12): 1503-8.
10. Koufman JA, Amin MR, Panetti M. Prevalence of reflux in 113 consecutive patients with laryngeal and voice disorders. Otolaryngol Head Neck Surg, 2000; 123(4): 385-8.

11. Qadeer MA, Swoger J, Milstein C, Hicks DM, Ponsky J, Richter JE i wsp. Correlation between symptoms and laryngeal signs in laryngopharyngeal reflux. Laryngoscope, 2005; 115(11): 1947-52.

12. Domeracka-Kołodziej A, Grabczak EM, Dąbrowska M, Lachowska M, Osuch-Wójcikiewicz E, Niemczyk K. Skala Warszawska A-E oceny endoskopowych zmian w krtani związanych z refluksem gardłowo-krtaniowym Korelacja ze skalą patologii refluksowej (RFS). Otolaryngol Pol, 2014; 68(4): 189-95.

13. Zaleska-Kręcicka M, Wosko-Czapnik D, Kręcicki T. Objawy laryngologiczne u chorych z chorobą refluksową przełyku. Otolaryngol Pol, 2003; 57(6): 819-22.

14. Włodarczyk E, Jetka T, Raj-Koziak D, Panasiewicz A, Szkiełkowska A, Skarżyński PH i wsp. Diagnosis of laryngopharyngeal reflux in children with voice disorders using 24-hour pharyngeal $\mathrm{pH}$ monitoring. Int J Pediatr Otorhinolaryngol, 2019; 121: 188-96.

15. Włodarczyk E, Miaśkiewicz B, Raj-Koziak D, Szkiełkowska A, Skarżyński PH, Skarżyński H. The application of 24-hour pharyngeal pH-monitoring and Reflux Finding Score and Reflux Symptom Index questionnaires in the diagnostics of laryngopharyngeal reflux. Prz Gastroenterol, 2019; 14(4): 274-82. 